\title{
É inclusão com exclusão? Sobre os entrecruzamentos de gênero, raça $e$ sexualidade no espaço escolar
}

\author{
ANA PROFÍRIO
}

UNIVERSIDADE FEDERAL DE ALAGOAS (UFAL), MACEIÓ/AL, BRASIL

HTTP://ORCID.ORG/0000-0002-3840-2860

\section{Introdução}

Este artigo busca refletir sobre os processos de inclusão e exclusão colocados em curso pela instituição escolar a partir dos entrecruzamentos de gênero, sexualidade, raça, classe e religião. Também procura refletir sobre o fazer etnográfico a partir da relação da pesquisadora com os interlocutores da pesquisa, pensando os (des)encontros dos respectivos marcadores de diferença dos sujeitos. Os dados aqui apresentados derivam de pesquisa ${ }^{1}$ em que discuto os modos de operacionalização das diferenças pela instituição escolar e a centralidade dela para o exercício de uma condição juvenil em certos segmentos sociais (Profírio, 2019). O conceito de interseccionalidade é imprescindível para a análise aqui pretendida, pois permite vislumbrar o entrecruzamento das opressões sociais considerando as restrições ou potencialidades nas trajetórias dos sujeitos a partir do encontro de distintos eixos de subordinação (Crenshaw, 2002).

1 Agradeço à Coordenação de Aperfeiçoamento de Pessoal de Nível Superior (Capes) pela concessão da bolsa durante todo o período de realização do mestrado. 
Ao decorrer de um ano, entre abril de 2017 e abril de 2018, acompanhei semanalmente ${ }^{2}$ a rotina de jovens lésbicas, gays, travestis e transexuais em uma escola "inclusiva” ${ }^{3} \mathrm{em}$ termos de gênero e sexualidade. A instituição Manoel de Barros ${ }^{4}$ é uma escola pública da rede estadual de Alagoas e faz parte de um grande complexo educacional, localizado na parte baixa da cidade de Maceió, próximo ao centro, abrangendo estudantes de distintos bairros da periferia e municípios do interior do estado de Alagoas.

Minha inserção etnográfica começou bem antes da realização da pesquisa propriamente dita. Durante a graduação atuei nesta escola enquanto bolsista do Programa de Iniciação à Docência (PIBID) na disciplina de Sociologia. Já nesse período chamava minha atenção a grande visibilidade de sujeitos e expressões de gênero e sexualidade não heteronormativos naquele espaço pedagógico, em contraste com o que observava em outra escola que pesquisava, caracterizada por violência homofóbica e pelo silenciamento das expressões homoeróticas e de transgeneridade. Ficava curiosa sobre como instituições públicas que ofertavam a escolarização para um grupo semelhante, jovens não brancos e periféricos, lidavam de forma distinta com a questão da homofobia.

Neste artigo discuto os processos de inclusão e exclusão realizadas no contexto escolar a partir dos diferentes sujeitos que compõem a instituição, considerando a articulação dos marcadores sociais da diferença de gênero, sexualidade, classe, religião e raça. Mostro que, apesar da proposta de "inclusão" em termos de gênero e sexualidade promovida pela escola, esta apresentava um conjunto de contradições significativas, pois ignorava as múltiplas posicionalidades dos sujeitos, promovendo, assim, uma inclusão parcial e, portanto, excludente. A seguir, descrevo os processos de inclusão e exclusão em diferentes instâncias na escola: num grupo religioso cristão coordenado pelos jovens estudantes, nas propostas de combate à homofobia por parte da gestão escolar e nas interações entre as/os jovens não heteronormativos a partir de "resenhas" que envolviam elementos raciais.

\section{O juventude para Cristo}

O fato da instituição Manoel de Barros ser "inclusiva” em termos de gênero e sexualidade não significava a ausência da homofobia, mas expressões sutis de preconceito. Um conjunto de situações ajudava a vislumbrar a complexidade da inclusão proposta e um dos espaços de maior tensão, neste sentido, era no âmbito do Juventude Para Cristo, daqui em diante denominado JPC. Trata-se de um grupo cristão formado por jovens estudantes católicos carismáticos, evangélicos pentecostais e neopentecostais, atuante na escola há mais de dez anos.

\footnotetext{
2 As situações aqui retratadas são resultado de observação participante e conversas informais no pátio, ginásio, refeitório e corredores da escola. A sala de aula não foi um espaço de observação, tratando-se de uma escolha metodológica no sentido de buscar uma maior aproximação com as/os jovens interlocutoras/es. Acerca desta escolha, é importante lembrar que uma das principais contribuições da Antropologia ao campo da Educação é a reflexão sobre como os processos pedagógicos estão para além das experiências de escolarização e seus modos formais de ensino e aprendizagem (Gusmão, 1997). No âmbito da Antropologia da Educação, pensar o universo escolar em articulação com outras instâncias pedagógicas, ou a existência de saberes na escola não restritos aos da sala de aula faz parte da complexidade de se fazer etnografias neste espaço. Assim, destaco o trabalho de Pereira (2016) no qual a reflexão sobre as experiências juvenis periféricas envolveu o cotidiano escolar dentro e fora da sala de aula, junto a outras esferas de socialização, as redes sociais, por exemplo.

3 As aspas demarcam o discurso de interlocutoras/es.

4 Todos os nomes próprios dos interlocutores, bem como o do local da pesquisa, são fictícios.
} 
O grupo promovia cultos, peças teatrais nas quais veiculam mensagens antidrogas, entrega de panfletos com escritos bíblicos, dentre outras ações de evangelização realizadas no espaço escolar durante o intervalo e nas aulas vagas. Contava com uma participação significativa em suas atividades das/ dos estudantes de modo geral e, especialmente, daquelas/es que escapavam da heteronormatividade. Gisele, uma jovem travesti, cantava nos cultos promovidos pelo grupo; outras/os jovens gays e lésbicas também ajudavam na organização das atividades, sobretudo por meio da divulgação dos dias e horários em que as ações seriam promovidas.

As/os jovens integrantes do JPC apresentavam posicionamentos distintos sobre a homossexualidade, da condenação à homofobia e ao machismo a falas que remetiam às considerações de Natividade e Oliveira (2013) sobre a homofobia religiosa ou pastoral, expressa através de uma ética de cuidado e de condenação da homossexualidade na qual se valoriza o sujeito que se submete a uma suposta "restauração sexual” e testemunha acerca disto. Um exemplo significativo ocorreu quando Gustavo, um jovem que por muito tempo se descreveu enquanto gay para toda a escola, passou a namorar uma colega de sala. Enquanto alguns especulavam que o rapaz pudesse ser "bi", o próprio jovem dizia estar surpreso com o afeto que sentia, levando-o a repensar de forma significativa a própria sexualidade. Alguns integrantes do JPC utilizavam a situação para falar sobre as "restaurações que Deus é capaz de realizar na vida dos sujeitos". O rapaz, entretanto, negava que a religiosidade tivesse alguma influência sobre suas "escolhas" afetivas.

Outro fato que gerou grande repercussão dentro e fora do JPC, provocando discussões inflamadas em toda a escola, foi o processo de "saída do armário" e, posteriormente, de "transição de gênero" de uma das lideranças do grupo. Amanda, que passou a chamar-se Fábio, deixou o JPC devido à pressão de alguns colegas que consideravam "inadmissível" que continuasse ocupando o cargo enquanto "lésbica" e posteriormente "homem trans" - muito embora outras/os jovens da escola não vissem qualquer problema nisto. As disputas e discussões em torno de sua saída ou permanência levaram à interrupção das atividades do JPC por quase um semestre.

É difícil evidenciar a complexidade dos posicionamentos das/dos jovens do grupo religioso diante do fato sem cair em certos dualismos por si só reducionistas, como dizer que o grupo se dividia entre progressistas e conservadores, o que a descrição até agora realizada poderia fazer pensar. Por essa razão, considero importante mencionar que o controle sobre o gênero e a sexualidade ocorria também para com as/os jovens heterossexuais, a partir da condenação de certas expressões afetivas e sexuais. No caso de Amanda/Fábio, por exemplo, ainda existiam aquelas/es que defendiam sua permanência no grupo pela capacidade e competência do jovem na organização das atividades, mas não deixavam de assumir um discurso de condenação acerca de suas "escolhas sexuais".

Sobre a presença de jovens lésbicas, gays, travestis e transexuais no JPC, em distintos momentos perguntei aos sujeitos como poderiam participar e até mesmo promover as atividades do grupo, considerando os discursos depreciativos acerca da homossexualidade e transexualidade que se tornaram mais explícitos com a situação de Amanda/Fábio. As/os jovens reconheciam o preconceito por parte de alguns colegas, mas diziam que isso não expressava a totalidade do JPC. Para muitos, o grupo reli- 
gioso estudantil era o único espaço que permitia a vivência da religiosidade, algo do qual sentiam falta desde o rompimento com as suas respectivas igrejas.

A "saída do armário" ou a "transição de gênero" e, às vezes, as duas situações de forma concomitante, eram descritas enquanto o começo de um processo de expulsão nada sutil do universo religioso. $\mathrm{O}$ preconceito sofrido no JPC era descrito enquanto "brando" se comparado a outras vivências, nas quais situações de violência física eram o marcador mais significativo da homofobia, algo que não ocorria no JPC e parecia conferir ao grupo religioso estudantil uma perspectiva positiva por parte dos sujeitos.

As/os jovens classificavam o JPC enquanto um espaço mais "cultural" que propriamente "religioso", algo reiterado por parte da direção escolar. As diretoras ${ }^{5}$ Carla e Fernanda afirmavam que não havia envolvimento de lideranças religiosas ou de igrejas, sendo uma regra da instituição escolar que o grupo fosse comandado apenas por jovens estudantes. Na perspectiva de alguns membros da escola, a auto-organização do grupo fazia com que o JPC não ferisse o princípio de laicidade que deveria regular os estabelecimentos públicos de ensino. Quem ia na contramão destes argumentos era a diretora Cristina: em sua visão o grupo feria, sim, o princípio da laicidade e, por isso, não deveria sequer existir, sendo descrito enquanto uma "herança" da antiga gestão escolar, "cristã e conservadora".

De qualquer forma, a religiosidade transcendia a atuação do JPC se expressando na própria lógica de inclusão da instituição escolar para com as/os jovens gays, lésbicas, travestis e transexuais. A linguagem utilizada para o combate à homofobia revelava certa ética cristã mesclada aos direitos humanos, sendo os limites de cada uma difícil de delimitar, como buscarei explorar a seguir.

\section{"A escola inclusiva" e algumas considerações sobre "acolhimento"}

Como mencionado, o colégio Manoel de Barros localizava-se próximo ao centro da cidade e parte considerável das/dos estudantes moravam em bairros distantes do espaço escolar, o que era apontado como uma das razões para a construção de uma escola "diversa" e "inclusiva". Em distintos momentos as/os jovens relatavam as dificuldades de expressarem a sua orientação sexual ou identidade de gênero em escolas de "bairro". O fato de colegas de classe também serem os seus vizinhos tornava a possibilidade de "saída do armário" impossível, visto que rapidamente tal informação poderia chegar ao conhecimento de toda a vizinhança e especialmente de pais, mães ou responsáveis. O deslocamento físico provocava, pois, deslocamentos subjetivos entre as/os jovens e a escola Manoel de Barros ficou rapidamente conhecida como a "escola gay" do complexo educacional.

A noção de escola "inclusiva" utilizada de forma recorrente pelos interlocutores da pesquisa para descrever a instituição chamava atenção para o deslizamento da categoria e para a necessidade de um espaço escolar que considerasse outras diferenças para além da deficiência. O processo de construção da "escola inclusiva" era descrito enquanto um ato de "fora" para "dentro", surgido a partir da visibilida-

5 As diretoras trabalhavam em regime de escala, revezando-se nos turnos matutino, vespertino e noturno. 
de de expressões de gênero e sexualidade não heteronormativas, e das reinvindicações de alguns jovens estudantes descritos enquanto "militantes".

Dentre estas/es se destacava Gisele, uma jovem travesti extremamente popular entre os colegas devido a sua atuação artística no JPC e em outras atividades da escola. Ela era apontada enquanto referência por docentes e discentes da "causa LGBT" - sigla para Lésbicas, Gays, Bissexuais, Travestis e Transexuais, termo amplamente utilizado por estudantes com perfil "militante", com discursos mais afinados às pautas do movimento. Gisele foi a primeira estudante da instituição a realizar o processo de "transição de gênero" e a reivindicar entre colegas e profissionais da instituição o combate à homofobia.

Gisele era figura constante na Direção e Coordenação escolar denunciando situações discriminatórias e exigindo alguma intervenção diante delas. Em seu primeiro ano no Ensino Médio, as reinvindicações de Gisele não resultaram em qualquer resposta por parte dos gestores da instituição; em seu segundo ano, porém, com a mudança da direção escolar, suas demandas passaram a ser atendidas pelo trio diretor - formado por Cristina, Carla e Fernanda - no escopo de gestão pautada pelo discurso de "acolhimento" que englobava os "homoafetivos".

Uma das diretoras, Cristina, descrevia-se enquanto "homoafetiva", afirmando estar casada com uma mulher há quase dez anos. Apesar de seu envolvimento direto com a questão, ela ponderava, no entanto, que a "inclusão" a este grupo era mais resultado de sua preocupação com a educação de modo geral. A escola, para ela, deveria ser um espaço para todas/os, mencionando também outras formas de preconceito existentes, dentre elas o racismo, que levaria à evasão de jovens negros/as da instituição escolar.

As outras diretoras, por sua vez, mencionavam suas respectivas experiências em sala de aula com estudantes "homoafetivos" para o seu "despertar" na questão do combate à homofobia. Relatavam casos de exclusão familiar e outras formas de violência para com estes estudantes que as marcaram significativamente em sua carreira docente e viam no exercício da gestão escolar uma oportunidade para a mudança desse quadro. Carla também contava em seu currículo com a formação em gênero e diversidade, e dizia ter sido o período de produção da dissertação de mestrado (sobre as dificuldades de abordar gênero e sexualidade no espaço escolar) outro momento significativo para perceber as faces da discriminação. O professor orientador do trabalho era "abertamente gay" e alvo constante de "piadas e comentários depreciativos" por discentes e docentes.

A noção de "acolhimento" que orientava o discurso desta equipe diretora sobre as ações empreendidas para permanência de jovens "homoafetivos" no espaço escolar ganha outros matizes quando observamos a semântica religiosa que pode acompanhar este termo. Carla e Fernanda, por exemplo, destacavam sua formação cristã enquanto um aspecto importante para o aprendizado sobre a necessidade de promover o "acolhimento" aos excluídos. No discurso das diretoras, o termo aparecia mesclado a noções importantes no âmbito dos direitos humanos, a partir de sua junção com palavras tais como respeito à diversidade, diferença e inclusão. A religiosidade transcendia, pois, os limites do grupo estudantil JPC.

Nenhuma das duas diretoras citava as estudantes lésbicas, ou jovens bissexuais, ao falar sobre as vítimas de homofobia no espaço escolar; era Cristina quem fazia menção a estes sujeitos. Mas, no geral, 
a gestão estava de acordo quanto a que a proposta de combate à homofobia na escola não buscava "fazer a cabeça de ninguém", ressaltando que cada um tem o direito a "pensar o que quiser sobre a homossexualidade", porém no espaço público "não se pode expressar certas opiniões, afinal todos devem ser respeitados". Estas ponderações me remetem ao trabalho de Seffner (2013: 157) que, a partir da observação de cenas do cotidiano escolar, buscou discutir projetos e propostas de inclusão voltadas ao gênero e à sexualidade em escolas públicas de Porto Alegre. Ele observou que apesar da boa intencionalidade de certas ações de enfrentamento à homofobia com base na noção de tolerância, estas podem gerar efeitos contraditórios e, às vezes, poucos eficazes no combate às desigualdades. O não questionamento da norma e o seu privilégio de invisibilidade só a reforçam.

Pude compartilhar este mesmo entendimento junto aos interlocutores de minha pesquisa em diferentes momentos durante o trabalho de campo. Um deles relaciona-se à existência de um terceiro banheiro para estudantes travestis e transexuais. Com frequência eu perguntava aos estudantes em que medida isso proporcionava a fuga da "pedagogia do insulto" ou poderia ser um reforço da "heteronorma" (Sampaio, 2015). As/os jovens discordavam que pudesse ser uma forma de "segregação" e relatavam que o banheiro proporcionou "segurança", pois eram discriminadas/os no banheiro comum. Além disso, comentavam que o constrangimento de fazer uso do espaço não era apenas dos outros, mas delas/es próprios, sentindo-se "alienígenas" no espaço convencional. Um jovem gay dizia não achar certo uma "travesti" fazer uso do "banheiro feminino", pois não era dotada de "vagina" e poderia assim constranger as garotas.

O uso do banheiro não era o único momento de criação de um espaço à parte: também existia a "fila das gays", que consistia na formação de um alinhamento específico para jovens "afeminados", travestis e transexuais receberem o lanche. Antes dela os sujeitos aguardavam junto aos demais numa fila única para entrar no refeitório. Mas "gays afeminadas" e travestis eram apalpadas por outros estudantes enquanto aguardavam. Gisele então fez uma reclamação à direção escolar e a criação de uma fila à parte foi o modo encontrado pela gestão para intervir nas situações de assédio. Quando questionava se o melhor não seria conversar e responsabilizar, de alguma forma, os rapazes que realizavam esses atos, ao invés de se criar um espaço à parte, ouvia que isso poderia piorar a situação e que aquela solução era a melhor para o caso. Mais uma vez, as/os jovens citavam experiências escolares anteriores nas quais foram vítimas de violência e a direção/coordenação não propôs qualquer solução.

As/os jovens, apesar de seus elogios à instituição, não deixavam de relatar situações de preconceito e discriminação por parte de colegas e docentes no Manoel de Barros. Amanda, ao relatar uma experiência nesse sentido ( situação ocorrida antes da "transição de gênero", por essa razão uso do artigo feminino), dizia que um professor impediu-a e a outra colega de assinarem a lista de frequência. Para ela, não havia nenhuma razão para o impedimento além de uma atitude de preconceito do professor, pelo fato dela e da colega serem lésbicas. Ao confrontar o professor no término da aula e perguntar por que teria sido impedida de assinar a lista, ele ficou em silêncio. Amanda chamou o docente de "homofóbico" e ele teria respondido de maneira irônica "nunca neguei que fosse". As situações no geral eram descritas enquanto "pontuais", algo fora da "rotina", mas nem por isso deixavam de ser mencionadas de forma recorrente pelas/os jovens. Destacavam-se os relatos sobre reclamações de docentes em sala de 
aula acerca da escola, afirmando que a instituição havia deixado de ser "tradicional" ou um "lugar de respeito", discurso este acompanhado de olhares percebidos como ameaçadores aos jovens não heteronormativos.

\section{"O coito: as travas, os machos, as gays e as rachas" no espaço escolar}

Devido aos conflitos relacionados à discussão sobre a permanência ou não de Amanda/Fábio no grupo religioso estudantil, as atividades do grupo foram interrompidas por quase um semestre. Dessa forma, minha atenção se voltou a Gisele, jovem travesti, dotada de um posicionamento mais crítico acerca da homofobia entre as/os colegas do grupo religioso. Ela desempenhava papel central no debate das questões LGBT na escola e tornou-se uma interlocutora privilegiada no processo de pesquisa. A jovem e seu grupo de amigas/os, chamado por ela de "coito", foram as/os jovens com as quais estabeleci maior proximidade durante o hiato das atividades do JPC.

Gisele realizava uma divisão de seu grupo de amigas/os a partir de uma nomenclatura própria. Existiam as "travas", composto por ela mesma e Carlinha, designação para quem fazia uso de hormônios femininos e apresentava seios avantajados, quadris largos e o cabelo na altura da cintura. Existiam também as "gays", rapazes afeminados que Gisele identificava como homossexuais, como Breno, Gustavo e Bruno/a, o integrante mais recente do "coito". Bruno/a se descrevia na maior parte das vezes utilizando artigos femininos, mas afirmava não fazer diferença ser chamado no masculino ou feminino. Faziam parte ainda do "coito" os "machos", termo utilizado para descrever os rapazes heterossexuais de forma geral e que não apresentavam uma performance atípica de gênero, em referência a Fernando, Valter e Ricardo, os garotos mais próximos a Gisele.

Rute era a única amiga cisgênero ${ }^{6}$ de Gisele, que geralmente se referia a todas as outras jovens da escola como "rachas", um termo pejorativo para descrever mulheres cisgênero. Para diferenciar a amiga das demais, dizia que Rute era uma "racha de respeito". Eu também ganhei uma atribuição por parte de Gisele passando a ser chamada de "amapô", termo também empregado para descrever mulheres cisgênero.

O "coito" revelava aspectos até então não pensados acerca dos processos de "inclusão" e "exclusão" no espaço escolar. Uma destas exclusões e tensionamentos se relacionava ao JPC. A situação de Gustavo namorando uma garota, como mencionado anteriormente, foi apropriada pelos estudantes que frequentavam o grupo religioso a partir de uma narrativa de restauração sexual, negada pelo rapaz. $\mathrm{O}$ anúncio do relacionamento coincidiu com a participação de Gustavo no culto de retorno do JPC, o que contribuiu para a consolidação de uma narrativa sobre a "cura gay". No âmbito do "coito", contudo, alguns colegas expressavam um posicionamento crítico sobre Gustavo, afirmando que Gisele nunca se rendeu à homofobia do JPC como ele, supostamente, estava fazendo.

6 A cisgeneridade pode ser resumida como a identidade que abarca os sujeitos que se identificam com o gênero que lhes foi determinado no nascimento (Vergueiro, 2015:45). 
Gisele, a única do "coito" a participar de modo ativo do JPC, negava que o amigo estivesse passando por uma "cura gay" e criticava quem fizesse afirmações nesta direção. Ela via no relacionamento de Gustavo um modo de o jovem agradar aos familiares. Não deixava de expressar frustração com o relacionamento do amigo de diferentes modos: às vezes não falava com o rapaz, noutras se dirigia a ele de forma irônica, questionando as razões pelas quais o jovem ainda andava com ela e outras/os jovens LGBT, afinal se ele não era mais uma das "gays", não deveria fazer parte do "coito".

Com exceção da situação envolvendo Gustavo, os conflitos do "coito" se distanciavam das divisões e controvérsias no âmbito do JPC, evidenciando modos de inclusão e exclusão que articulavam, para além de gênero, sexualidade e religiosidade, também os marcadores de raça e classe. Gisele e Carlinha vivenciaram diferentes atritos pelo fato de a segunda negar o termo "travesti", descrevendo-se enquanto uma "gay afeminada". Além disso, a jovem não compartilhava da veia "militante" de Gisele, mostrando-se irritada com os discursos politizados da amiga sobre a importância de as "gays" darem seu "testemunho".

Carlinha inclusive se recusava a participar da pesquisa, dizendo acreditar que este tipo de trabalho "não serve pra nada e não muda nada". Nunca insisti sobre a sua participação no projeto, pois não conseguia formular uma resposta digna às suas indagações. Seu incômodo, porém, não era só com a pesquisa que estava realizando. Carlinha demonstrava desconforto com um conjunto de dinâmicas de caráter racial no âmbito do "coito" que passaram também a me afetar profundamente e me paralisavam enquanto pesquisadora.

No "coito" certa ambiguidade racial parecia ser almejada pelas/os jovens, algo que não vislumbrava no JPC, cujo racismo era de caráter religioso e não estético a partir especialmente da discriminação às religiões de matriz africana. No âmbito do JPC, aproximar-se de uma aparência branca ou nem tão negra era recorrente nos discursos, nas pequenas intervenções estéticas realizadas pelos sujeitos e, especialmente, nas modificações corporais voltadas à transição de gênero. Em termos de cor, os únicos integrantes do "coito" que se viam enquanto brancos eram Rute e Gustavo. As/os jovens do "coito" se descreviam apenas em termos de cor, enquanto "morenos" ou "bronzeados", colocando a possibilidade de não "ser" de dada cor, mas de "estar" em um dado gradiente 7 .

Meu corpo era apropriado pelo grupo, deixando-me absurdamente desconfortável. Minha aparência era excessivamente elogiada, sendo descrita enquanto "bonita" por apresentar uma pele "morena clara", cabelo liso "natural"” e um rosto dotado de traços "finos". Em resumo, eu era "bonita” para o grupo por ser "quase branca" ao olhar deles, ou "nem tão negra assim". Enquanto parda, minha negritude sempre é relacional e contextual, podendo ser lida enquanto mais ou menos negra a partir de quem me vê e do espaço no qual estou inserida. Sempre tive certeza de que não sou branca, mas quão negra sou é alvo de controvérsia. De qualquer forma, me afirmo negra, entendendo esta categoria para além da cor, enquanto uma identidade política.

7 As considerações das/dos jovens exemplificam a discussão sobre colorismo. Norwood (2015) afirma que o colorismo não chega a ser racismo propriamente dito, mas se relaciona com ele. Para simplificar a distinção: quando uma loja se recusa a contratar funcionários negros, estamos diante de um caso envolvendo racismo; quando sujeitos negros são contratados, desde que tenham um tom de pele mais claro e outros traços associados aos brancos, trata-se de uma situação envolvendo colorismo.

8 O termo "natural" era usado para descrever os cabelos de textura lisa sem uso de produtos alisantes ou relaxantes. 
Sobre as/os demais integrantes do grupo, eu os enxergava "negras/os", ou seja, "pardos e pretos", indo das variações de marrom ao total escurecimento. É importante mencionar que a categoria "pardo/a" é parte de uma abordagem censitária do país. O Instituto Brasileiro de Geografia e Estatística (IBGE) historicamente interpretou a população brasileira como sendo tão miscigenada que seria impossível uma abordagem pautada em ancestralidade, por essa razão privilegia categorias de cor e fenótipo (Bailey, 2016). O termo "pardo/a" é alvo de críticas e controvérsias no âmbito movimento negro, visto enquanto uma tentativa de "embranquecimento" da população. Guimarães (2008) explora os (des)encontros entre categorias nativas, censitárias e de militância social, considerando que a identificação racial no cotidiano pode envolver elementos de cor, em predomínio aos de identidade. Alguém pode se descrever "moreno" ou "pardo" enquanto cor, e assumir ou não o termo "negro" em seu uso político.

Outro alvo de discussão é se "pardos" seriam ou não alvo de racismo. Em resumo, pardo era uma categoria da pesquisadora, mas que não fazia sentido para os sujeitos da pesquisa. Quando dizia aos interlocutores que "pretos e pardos" formam a população negra do país e por essa razão sou negra, lidava com um imenso estranhamento por parte daquelas/es jovens. Numa destas ocasiões fui, inclusive, corrigida de forma violenta por Gustavo, que me chamou de "morena" como se a palavra negra fosse algo ofensivo.

Se em relação ao gênero e à sexualidade conseguia tensionar o que estava sendo dito e realizado pelos sujeitos, sobre a questão racial silenciava, silêncio este uma espécie de grito inarticulado na garganta.

\section{“As resenhas", ou todo mundo não é "negro", exceto quem é}

Um aspecto central do intervalo das aulas consistia na realização das "resenhas", termo utilizado pelos jovens para descrever práticas de zoação e brincadeiras, realizadas especialmente entre aquelas/es com quem compartilhavam de algum grau de intimidade ou proximidade. Pereira (2016), ao abordar este tipo de interação, discute como tais práticas não cabem numa perspectiva totalmente patologizante, pensando o bullying, por exemplo. As zoações encerram uma imensa ambivalência e, apesar de seu caráter conflitivo, buscam de certa forma agregar os sujeitos. A zoação entre jovens estudantes com os quais o autor realizou a pesquisa baseava-se especialmente em alguma dimensão corporal. O mesmo ocorria no caso aqui descrito.

As principais "resenhas" envolviam processos de racialização, atribuindo à negritude uma dimensão pouco desejável. A depreciação do cabelo crespo e de outros traços, como nariz largo, pele escura, ocorriam de forma frequente e podem ser interpretadas a partir das considerações de Nogueira (2007 [1954]) sobre o "preconceito de marca”. Ao traçar um paralelo entre as relações étnico-raciais brasileiras e o contexto estadunidense, o autor observa que o preconceito no Brasil se expressa não pela exclusão dos sujeitos, mas por seu preterimento a partir da aparência e dos traços físicos.

Neste sentido, era bastante comum às/aos jovens realizarem piadas sobre o cabelo crespo desaprovando estudantes que não o alisavam. Certa vez, Gustavo arrancou gargalhadas dos "machos" ao chamar de "presepada" e comparar com uma vassoura o cabelo black power de uma colega de sala. $\mathrm{O}$ 
jovem ainda fez questão de exaltar seu cabelo liso "natural" afirmando ser muito "desleixo" uma mulher "não cuidar" do cabelo. Em seguida, os "machos" dedicaram boa parte do intervalo a dizer coisas semelhantes. Fernando, por exemplo - que se descrevia "moreno" e às vezes "muito bronzeado" (eu lia-o preto) -, afirmava considerar "feio" ostentar o cabelo crespo. O rapaz vivia com a cabeça raspada, acreditava que seu cabelo também fosse crespo.

Ao refletir sobre a importância do cabelo para a identidade negra, Rocha (2016) observa que a manipulação dos fios crespos, tornando-os lisos, reflete a valorização de um padrão estético de "branqueamento" na realidade brasileira. O cabelo crespo e a pele escura são geralmente percebidos como distantes da "boa aparência" e os sujeitos acabam por lidar com um conjunto de situações depreciativas acerca de sua corporeidade, acarretando inclusive a evasão escolar ou profissional. $\mathrm{O}$ ato de alisar o cabelo, neste sentido, poderia ser uma tentativa de escape a estas situações.

O alisamento capilar era recorrente entre as/os jovens, mas não os livrava totalmente de ser alvo das "resenhas" de caráter racializado. Quando não depreciavam o cabelo crespo, os discentes elencavam outros aspectos da corporeidade negra a exemplo do que ocorreu com Breno, uma das "gays" que, logo após ter alisado o cabelo, lidou com um conjunto de "brincadeiras" por parte dos "machos". Em tom de provocação, os rapazes lhe diziam: "Olha só ele, alisou o cabelo ruim, foi? Agora está com o cabelo bom? Mas não tem jeito não. E essa venta aí, enorme de nego! Pra que essa venta?”. Breno pediu que os colegas o deixassem em paz e saiu de perto do grupo, uma resposta que era exceção a este tipo de dinâmica.

Tais situações arrancavam gargalhadas entre as/os jovens que faziam parte do "coito". Para mim, a possibilidade do riso era totalmente desconcertante e tensa. Grande parte do estranhamento que direcionava meu olhar para essa dimensão racial advém, justamente, do fato de que poucos pareciam afetados por esse tipo de "resenha". Carlinha, uma das poucas jovens que parecia se reconhecer enquanto negra, tinha um entendimento distinto sobre essas situações. Para ela "toda resenha tem um fundo de verdade”.

A partir de minhas experiências com Gustavo, compreendi melhor o que Carlinha estava expressando. Ele realizava os comentários com os quais era mais difícil lidar, sempre como resposta às afirmações de Gisele sobre homens negros. A relação de Gisele com os seus amigos "machos” era carregada de ambiguidade, repleta de insinuações sexuais de ambas as partes, que não permitiam chegar a uma conclusão sobre a concretização de algum tipo de parceria afetivo-sexual entre eles. Gisele dizia que os rapazes negros têm "janela alta” (expressão usada para se referir a pênis avantajado) e, por esse motivo, ela "adorava um negão"; em resposta, os "machos" pediam que Gisele lhes desse uma chance. Suas falas faziam referência às representações no imaginário brasileiro sobre a sensualidade de homens negros, segundo metáforas de volume, virilidade e desempenho sexual (Simões, França \& Macedo, 2010).

Diante dos comentários de Gisele, Gustavo expressava absoluta reprovação, associando à pele negra a "sujeira". Por mais que tentasse disfarçar meu desconcerto e assumir uma postura blasé, nem sempre era bem-sucedida nessa tarefa. Certa vez, Gustavo percebeu que estava desconfortável e me provocou, em tom de "brincadeira", dizendo: "Eita, bichinha. É muito inocente, está chocada". De forma irônica respondi que estava mesmo e que ele deveria "limpar a boca porque o veneno estava escorren- 
do". Gustavo ficou por muito tempo rindo, ao passo que assumi o mesmo tom de zoação utilizado para as "resenhas" e me lembrei o que Carlinha costumava dizer. Brincando se diziam coisas sérias.

Esta foi uma das poucas situações em que consegui responder. Geralmente ficava paralisada. Em um primeiro momento, pensei que meu silêncio dizia respeito à noção idealizada do que significa ser pesquisadora, no qual a realização da pesquisa está acima de qualquer coisa. Este aspecto é desenvolvido por Daniel (2019), ao abordar a experiência de sofrer racismo no trabalho de campo durante a realização de uma pesquisa sobre imigração peruana. A autora chama atenção ao absoluto silêncio de nossa formação antropológica sobre o fato de pesquisadoras/es serem dotados de cor/raça. Tal como ela, eu estava familiarizada a pensar sobre o gênero no trabalho de campo e suas implicações, conseguia facilmente ter um posicionamento crítico sobre as minhas limitações e possibilidades enquanto mulher cis que não compartilhava das mesmas experiências afetivas e sexuais que as/os principais interlocutoras/es da pesquisa, mas nunca havia sido provocada a pensar sobre os efeitos de minha cor/ raça no fazer antropológico e me vi despreparada em relação a isso.

Me sentia triste e constrangida com as "resenhas" de modo geral e especialmente com o fato de minha aparência ser apropriada como parâmetro de beleza. Os dias de ida à escola eram emocionalmente exaustivos, me questionava por que não conseguia elaborar uma resposta às situações ou minimamente tensionar as "resenhas", como acontecia em relação às contradições da "escola inclusiva”. Sentia culpa em não exercer uma crítica, fornecendo respostas às situações de desigualdade racial, algo que em outros contextos já fui capaz de fazer.

Só ao ler Kilomba (2019) é que me concedi o direito de desculpa sobre meu silêncio, e entendi suas motivações para além da premissa de realizar a pesquisa acima de tudo. Ao analisar o racismo cotidiano, sendo as interações acima descritas um exemplo, a autora discute como o sujeito negro se silencia em vários momentos diante da desigualdade racial não por apatia ou submissão, mas pelo entendimento de que, devido às estruturas racistas, sua fala será desqualificada. Além disso, a experiência do racismo cotidiano só pode ser traduzida em termos de trauma. Um tipo de dor indizível do qual raramente se consegue palavras e símbolos correspondentes. $\mathrm{O}$ racismo cotidiano não é um momento isolado nas biografias, mas a atualização de um passado colonial repleto de desigualdade e sofrimento. Uma experiência que antecede o sujeito negro e ao mesmo tempo o ultrapassa em termos históricos e territoriais.

Kilomba (2019) promove um deslocamento bastante significativo acerca deste tipo de experiência. É comum nos indagarmos ou sermos indagadas/os sobre o que fizemos depois de um episódio racista, assumindo uma posição de que deveríamos ter reagido de alguma forma. Para a autora, essa pergunta deve ser de ordem secundária, sendo prioritário responder à seguinte indagação: o que o racismo fez ou faz comigo? Ao responder a esta pergunta o sujeito negro passa a ser sua primeira e única prioridade. A necessidade de sempre respondermos à discriminação criaria uma espécie de dependência na qual nos colocamos à disposição do sujeito branco, dando a ele a capacidade de possuir e controlar nossos corpos e mentes. 


\section{As "transições de gênero" e outros modos de se afastar da "negritude"}

A "transição" era um termo nativo utilizado para descrever distintas formas de experienciar o gênero, o que envolvia especialmente transformações corporais significativas a partir de processos de hormonização. Ao todo cinco jovens estavam em processo de "transição de gênero" no espaço escolar, mas nesta seção pretendo focar nas transições realizadas pelos integrantes do "coito", especificamente. Estas situações ajudam a vislumbrar a questão racial na escola e se conectam a outras transformações corporais mais sutis, com discursos que buscavam o afastamento da negritude, ou melhor, de uma visão estereotipada dela.

Era notável, por exemplo, o quanto Gisele estava "embranquecida” se comparada ao período anterior à "transição". O cabelo, antes escuro e cacheado, tornou-se liso e a cada semana mudava de tom parecendo mais claro devido às "luzes" (técnica de pintura capilar para tingir os fios de loiro). Antes de realizar os procedimentos capilares, Gisele se descrevia "morena”; após as intervenções, passou a ser descrita por colegas enquanto "galega" e se afirmava nesses termos. As intervenções na cor do cabelo modificaram a impressão acerca de seu tom de pele pardo. A jovem também fazia uso constante de maquiagem, a base no rosto sempre estava um tom acima de sua cor e contribuía para seu aspecto embranquecido.

Gisele costumava afirmar que a "trans padrão", ou seja, ela mesma, era branca com o cabelo liso e loiro. Traçava o que seria a trans fora do padrão citando uma amiga: "Ela é negra e tem um black. Tá fora da curva. A trans padrão é branca, cabelo liso de chapinha com luzes, mas ela (a amiga) faz sucesso, por ter assim uma beleza diferente, exótica”. Gisele comentava sobre a página no Facebook "Travestis e Transexuais Brasileiras" (Dias, 2012), elencando enquanto referências às travestis e transexuais vencedoras de concursos de beleza, cuja aparência atendia ao que chamava "trans padrão".

Este tipo de discurso era evocado como forma de aconselhamento a Bruno/a, que planejava no futuro iniciar seu processo de hormonização - não o percebendo, necessariamente, enquanto uma “transição de gênero", pois independente do uso de hormônios, já era uma "LGBT” e "mulher trans". Bruno/a via em Gisele sua inspiração. Ele/a apresentava o cabelo crespo curtinho e dizia não ver a hora de alisá-lo, porque o considerava muito "ruim" e "feio". Certa vez comentei com Bruno/a que cabelo tem textura e cor, não caráter, pra ser "bom ou ruim”, e que seu cabelo era bonito. Bruno/a discordou e respondeu que eu só dizia essas coisas por ter um “cabelo desejável”. Fiquei em silêncio, sem saber responder. Foi a primeira vez que entendi em profundidade o meu cabelo enquanto um privilégio.

Havia outros momentos dramáticos envolvendo o meu cabelo que, por ser liso, era objeto de certa apreciação. Respondia a um conjunto de interpelações sobre minhas madeixas: se utilizava apliques, se já havia feito uso de alisantes ou chapinha, se já havia pintado, etc. Ao negar todas as perguntas, recebia um olhar de admiração e até mesmo preces para evitar o "mau olhado". Toda a valorização do cabelo liso "natural", ou sem "química", fazia-me questionar o que era entendido pelo grupo em relação a essas duas dimensões. Nunca considerei meu cabelo "natural" ou sem "química”, pois o uso de xampu, 
condicionador, creme de pentear e diversos outros produtos alteram a "natureza" dos fios, às vezes de maneira tão drástica quanto o uso de alisantes.

Diversos pesquisadores (Rocha, 2016; Santos, 2017; Pontes, 2017) têm destacado o cabelo como um elemento importante para a reflexão sobre modos de performance ou não da negritude. Mizrahi (2019), ao refletir sobre as políticas de cabelo entre mulheres negras pensando a construção da persona feminina no funk carioca, demonstra como as diferentes formas de manipulação do cabelo podem ser resposta ao racismo cotidiano, e um modo de agência das mulheres que lhes permite acessar e circular entre diferentes espaços. A antropóloga debate, por exemplo, como os cabelos ambíguos de suas interlocutoras, que não eram propriamente lisos ou crespos, ficando em um "não lugar", propiciavam um modo de escape às representações mais tradicionais da negritude, de "cabelos afro" e também de um cabelo propriamente branco, liso.

No campo aqui descrito, a ambiguidade racial era alcançada a partir da junção de um conjunto de elementos corporais, em que o cabelo ganhava centralidade, mas não era o único aspecto. Se, no caso de Gisele e Bruno/a, as modificações capilares asseguravam a demarcação da feminilidade e a afirmação de um padrão estético eurocêntrico, nem todas/os poderiam ser bem-sucedidas/os no último aspecto. O tom de pele mais escuro tornava o "embranquecimento" e certa ambiguidade racial impossível para alguns. Isso ficava visível no caso de Breno, citado anteriormente, e de outras/os jovens negros que eram motivo de "piada" ao tentar aproximar-se de uma estética branca.

Ao contrário de Gisele, o processo de feminilização de Carlinha não envolvia o embranquecimento. Ao deixar seu cabelo crescer, Carlinha optou não pelo alisamento e sim pelo uso de penteados que valorizavam o cabelo crespo. As trancinhas rastafári eram, assim, a sua marca registrada. É interessante notar que enquanto a maior parte das/os jovens falava constantemente sobre alisar o cabelo crespo e demonstravam uma atitude de desprezo em relação à negritude, Carlinha expressava orgulho de sua cor/raça ao corrigir colegas que a chamavam de "morena", afirmando-se "negra".

Ela costumava compartilhar com as outras estudantes negras da escola técnicas de cuidado do cabelo crespo, especialmente entre as que estavam interessadas em interromper o uso de alisantes. Carlinha comentava de forma entusiasmada sobre salóes dedicados ao "cabelo afro" e descrevia a realização de um procedimento chamado "permanente afro". Trata-se do uso de produtos específicos para o cabelo crespo ou cacheado que busca dar "forma ao fio", acentuando os cachos. Esse tratamento pode estar associado à "transição capilar”, que consiste na interrupção de procedimentos químicos alisantes, estando às vezes atrelada a uma afirmação da identidade negra, visto que o uso do cabelo crespo pode ser um ato político (Pontes, 2017).

\section{A “periferia" é eufemismo de "negritude"?}

Durante o trabalho de campo o diálogo com os profissionais da escola foi pontual e esporádico. Conversei com as/os docentes quando explicava o meu retorno à escola e apresentava de forma resumida a pesquisa que estava realizando. Diante de meu objeto de análise ouvia, em resposta, que a homofobia "é coisa do passado" e uma questão "resolvida na instituição". As/os docentes apontavam, então, 
quais seriam os verdadeiros dilemas que a escola estava enfrentando: a "intolerância religiosa” sobre as religiões de matriz africana, sendo jovens estudantes "evangélicos" apontadas/os enquanto principais responsáveis por essa situação; a "indisciplina” dos rapazes que não levavam os estudos a sério e só estavam atrapalhando as aulas; e, por último, a presença da violência na escola, tendo como expressão máxima o "tráfico de drogas".

A negritude enquanto indesejável também era mobilizada nos discursos dos profissionais a partir da discussão sobre os jovens periféricos. O termo informava sobre percepções estereotipadas e discriminatórias acerca dos jovens rapazes negros. A experiência de ser morador da periferia fazia com que esses estudantes fossem descritos enquanto "vulneráveis" e "pauperizados" social/economicamente, ou associados a potenciais ameaças à ordem institucional devido a seu comportamento "indisciplinado", incluindo a possibilidade de associação a atividades ilícitas.

$\mathrm{Na}$ coordenação escolar vislumbrei, em vários momentos, as/os jovens "indisciplinadas/os". As ações que levavam os e as estudantes a esse espaço eram diversas: conversas durante a aula, uso do celular, desrespeito aos colegas, desentendimentos com os docentes. Era curioso perceber que a incidência dos rapazes era bem maior que a das moças, e, mais uma vez, eu via os sujeitos enquanto "negros". Mas nunca cheguei a perguntar se eles se percebiam nesses termos.

Ao refletir sobre o "enigma masculino no desempenho educacional", Pinho (2013) observa que há um descompasso entre a construção hegemônica da masculinidade e as expectativas de ser um "bom aluno". O autor menciona a importância de uma abordagem interseccional na qual gênero, raça e classe devam ser considerados condicionantes que interagem com a instituição escolar. Ao analisar a evasão de rapazes negros, o autor constata que, sendo o gênero a modalidade na qual a raça é vivida, a masculinidade negra porta um conjunto de contradições. Dessa forma, é importante pensar como essa masculinidade racializada lida com a escola e suas exigências, dentro da perspectiva de reprodução a partir de um arbitrário cultural (Bourdieu e Passeron, 2010).

A desconfiança sobre os "periféricos" não se resumia aos receios de docentes, mas também dos próprios discentes sobre certos colegas revelando aspectos da discriminação de gênero e racial ocorrida dentro e fora da escola. Um exemplo disso envolvia um $/ \mathrm{a}^{9}$ jovem estudante que pouco socializava com os colegas, evitava falar sobre qualquer dimensão da sua vida e especialmente sobre o seu processo de transformação corporal. Especulava-se que "ele/a” estaria realizando a mudança gradual do masculino para o feminino não por ser uma "travesti” ou "trans", mas para "passar por mulher" e enganar a Polícia:

\footnotetext{
- Olha o que eu sei dessa pessoa é o seguinte, era toda machinho antes. Mas aí um parente foi preso, por que era traficante. Foi um baita perrengue pra família. Ele deixou muitas dívidas e o pessoal ficou cobrando. Pra pagar o pessoal que o parente estava devendo, começou a fazer aviãozinho ${ }^{10}$, só que pra isso precisava de cobertura, né? E assim, tu já viu a cor? É preta... com [cabelo] moicano no tempo [antes da transição], cheia das pratas [em referência a cordões de prata], era muito visível pra polícia. Aí percebeu que a polícia não abordava muito as mulheres. Começou a se vestir, a se maquiar, e agora tá usando hormônios. (Diário de campo, 08 set. 2017).
}

$9 \mathrm{O}$ uso dos artigos femininos e masculinos diz respeito à mesma situação de Bruno/a.

10 Jovens que fazem transporte de drogas, em pequenas quantidades, dos traficantes para os usuários. 
O caso gerava debates sobre como se "ele/a" estaria se identificando com o feminino e gostando da experiência ou apenas "suportando" a situação. Alguns acreditavam que a transformação corporal nada tinha a ver com o envolvimento em atividades ilícitas, outros afirmavam que não era uma "travesti verdadeira" por estar modificando o corpo de forma "estratégica". As especulações sobre essa/e jovem ficavam restritas aos estudantes, não chegando ao corpo pedagógico. Aliás, nunca ouvi qualquer história por parte dos profissionais da escola sobre uma garota ou um rapaz branco envolvido em atividades ilícitas. E no nível de transformação corporal no qual a/o jovem se encontrava era descrito enquanto uma "jovem trans negra”.

Acho interessante tanto o fato de que as/os jovens estudantes e as/os profissionais da escola não estarem distantes dos sujeitos "periféricos", em termos de localidade, quanto o modo como a espacialidade informa sobre cor/raça. $\mathrm{O}$ processo de negação e não reconhecimento da própria negritude exemplifica a alienação a qual o sujeito negro é constantemente submetido. A negritude lida boa parte do tempo não com aquilo que ela é, mas com fantasias brancas sobre ela, que projetam os aspectos negativos e negados da própria branquitude no sujeito negro. Negras/os vivenciam constantemente o processo de alienação, pois as imagens de negritude com as quais se é confrontada/o são pouco realistas e nada elogiosas, tudo o que é desejável é associado ao branco (Kilomba, 2019).

\section{Sobre o “acolhimento" e inclusões parciais, não a título de conclusão}

A escola aqui descrita revela um conjunto de potencialidades e contradições no que se refere à "inclusão". Em parte tal proposta realizava um deslizamento significativo acerca de quem deve ser incluído, mobilizando outros marcadores sociais para além da deficiência. Contudo, uma abordagem verdadeiramente "inclusiva" deveria levar em conta os múltiplos pertencimentos dos sujeitos, caso contrário pode (re)produzir exclusões.

Acerca das/os jovens lésbicas, gays, travestis e transexuais, era inegável que os sujeitos estavam usufruindo de um espaço escolar mais democrático, considerando a proposta de "acolhimento" aos homoafetivos por parte da direção. O que não anula questionamentos sobre os modos como a ação estava a ser promovida e seus impactos de médio e longo prazo: se pensarmos a escola enquanto um lugar de produção de subjetividades, sobre a homossexualidade estava a ser construído um espaço de tolerância, talvez não replicado na próxima gestão escolar.

No âmbito do JPC, o grupo modulava os marcadores de gênero e sexualidade, a partir de pressupostos heteronormativos, e de raça em torno da discriminação às religiões de matriz africana. Já no que se refere ao "coito", as contradições que perpassavam as "resenhas" com alguns dos estereótipos, acerca de criminalidade compartilhados por docentes e discentes, ajudam a vislumbrar uma regulação de gênero que convergia para a valorização da feminilidade e branqueamento no espaço escolar. Butler (2014) discute como as proibições, mais do que coibir certas atividades, exercem outra função: a produção de parâmetros acerca dos sujeitos. 
A construção da escola democrática em termos de gênero e sexualidade, repleta de contradições nesse aspecto, ocorria em paralelo às discriminações raciais. As "gays" eram os únicos jovens rapazes negros não associados aos estereótipos de masculinidade ameaçadora, devido a sua feminilização. Gisele, com os processos de transformação capilar (luzes e alisamento), tornou-se "branca" na interpretação de alguns colegas, reforçando o modelo de feminilidade por ela almejada distante do que classificava "exotismo". A feminilização de Carlinha conferia valor positivo à sua cor/raça e ao seu cabelo. Por último, não deixava de pensar se a aproximação dos "machos" com as "gays" e "travas" seria uma estratégia dos rapazes para também se distanciarem dos estereótipos associados à masculinidade negra.

A interseccionalidade, enquanto proposta analítica, busca compreender a natureza da dominação, as relações de poder e as desigualdades dos grupos em conflito. Contribui, nesse sentido, com o entendimento das relações sociais de forma transversal, escapando de binarismos como "vítimas" e “opressores”, pois cada sujeito ocupa lugares de privilégios e opressão (Collins, 2019:318). Os estereótipos em torno da negritude no espaço escolar informam sobre a inseparabilidade de gênero, raça, sexualidade e religião, não podendo qualquer proposta de "inclusão" ignorar um destes marcadores com a possibilidade de produzir outras formas de "exclusão".

A questão racial na escola também foi uma redescoberta do ser pesquisadora. Medeiros (2018), ao descrever sua experiência enquanto antropóloga negra realizando pesquisa com policiais civis, explora como a produção do conhecimento antropológico é atravessada pelas posicionalidades de pesquisadores e pesquisados. A reflexão sobre tais posicionalidades, ou melhor, "locais de fala", possibilitou à autora uma compreensão aguçada dos privilégios, adversidades e riscos em suas interlocuções com os sujeitos. Até a realização da pesquisa de campo eu jamais havia refletido sobre que antropólogas/os são dotadas/os de cor/raça e que essa posicionalidade influencia não apenas a realização do trabalho de campo e a interlocução com os sujeitos, mas o modo como as situações serão interpretadas e apresentadas em termos de escrita. Se eu fosse branca, talvez tivesse visto as situações de modo distinto. Questionei em diferentes momentos se, no fundo, estava "problematizando" em excesso. O incômodo que não era compartilhado com as e os interlocutores da pesquisa deveria ser visto enquanto um problema?

Não posso dizer que os sujeitos se sentiam excluídos em termos de raça no espaço escolar, afinal eles não se percebiam negras/os e poucas vezes demonstravam-se incomodadas/os com as situações com exceção de Carlinha, cuja compreensão racial era distinta da de seus colegas. Foi graças a ela, que participou da pesquisa "não participando", que pude aprender as lições mais significativas do trabalho de campo. Assim, parei de pensar no meu desconforto enquanto mera projeção e aprendi a não mais ignorar minha subjetividade no processo de pesquisa, considerando essa característica uma importante ferramenta analítica.

\footnotetext{
Ana Profirio é Mestra em Antropologia Social pela Universidade Federal de Alagoas (UFAL) e Professora de Sociologia pela Secretaria de Estado da Educação de Alagoas (SEDUC-AL).
} 


\section{REFERÊNCIAS}

Bourdieu, P; Passeron, J-C. (2010). A Reprodução. Elementos para uma Teoria do Sistema de Ensino. Petrópolis: Vozes.

Butler, J. (2014). Regulações de gênero. Cadernos Pagu, 42, 249-274. http://dx.doi. org/10.1590/0104-8333201400420249

Collins, P. H. (2019). Pensamento Feminista Negro. São Paulo: Boitempo.

Crenshaw, K. (2002). Documento para o encontro de especialistas em aspectos da discriminação racial relativos ao gênero. Revista Estudos Feministas, 10(1), 171-188. http://dx.doi.org/10.1590/ S0104-026X2002000100011

Daniel, C. (2019). Morena: a epistemologia feminista negra contra o racismo no trabalho de campo. Humanidades e Inovação, 6(16), 23-34. Disponível em https://revista.unitins.br/index.php/humanidadeseinovacao/article/view/1825

Dias, K. L. (2012). Travestis e Transexuais Brasileiras. Disponível em: https://www.facebook.com/ TRAVESTISeTRANSEXUAISbrasileiras

Guimarães, A. S. A. (2008). Raça, cor e outros conceitos analíticos. In: O. Pinho \& L. Sansone (org.). Raça: Novas perspectivas antropológicas. (pp. 63-82). Salvador: Ed.UFBA.

Gusmão, N. M. (1997). Antropologia e Educação: origens de um diálogo. Cadernos CEDES, 18(43), 8-25. http://dx.doi.org/10.1590/S0101-32621997000200002

Kilomba, G. (2019). Memórias da plantação: episódios de racismo cotidiano. Rio de Janeiro: Cobogó.

Medeiros, F. (2018). Adversidades e lugares de fala na produção do conhecimento etnográfico com policiais civis. Cadernos de Campo, 26(1), 327-347. Disponível em https://www.revistas.usp.br/cadernosdecampo/article/view/142130

Mizrahi, M. (2019). As políticas dos cabelos negros, entre mulheres: estética, relacionalidade e dissidência no Rio de Janeiro. Mana, 25(2), 457-488. http://dx.doi.org/10.1590/ $1678-49442019 v 25 n 2 p 457$

Natividade, M.; Oliveira, L. de. (2013). As novas guerras sexuais: diferença, poder religioso e identidades LGBT no Brasil. Rio de Janeiro: Garamond.

Nogueira, O. (2007). Preconceito racial de marca e preconceito racial de origem: sugestão de um quadro de referência para a interpretação do material sobre relações raciais no Brasil. Tempo social, 9(1), 287-308. http://dx.doi.org/10.1590/S0103-20702007000100015 
Norwood, K. J. (2015). “If You Is White, You’s Alright....” Stories About Colorism in America. Global Studies Law Review, 14, 584-607. Disponível em: https://openscholarship.wustl.edu/cgi/ viewcontent.cgi $?$ article $=1547 \&$ context $=$ law_globalstudies

Pereira, A. B. (2016). A maior zoeira: experiências juvenis na periferia de São Paulo. São Paulo: Unifesp.

Pinho, O. (2014). Um enigma masculino: Interrogando a masculinidade da desigualdade racial no Brasil. Universitas Humanística, 77, 227-250. Disponível em: https://revistas.javeriana.edu.co/index. $\mathrm{php/univhumanistica/article/view/5945}$

Pontes, L. L. (2017). "Posso tocar no seu cabelo?” Entre o "liso" e o "crespo": Transição Capilar, uma (re) construção identitária? (Dissertação de Mestrado). Centro de Filosofia e Ciências Humanas, Universidade Federal de Santa Catarina, Florianópolis.

Profírio, A. L. G. (2019). Corpos como campos de batalha: uma etnografia sobre entercruzamentos de gênero, raça e sexualidade no espaço escolar em Maceió (Dissertaçãode de Mestrado). Instituto de Ciências Sociais, Universidade Federal de Alagoas, Maceió.

Rocha, N. G. da. (2016). Crespos: o cabelo como ícone da identidade negra. Memória e estética, a circulação de ideias e valores na realidade brasileira. Revista NEP, 1, 86-92. http://dx.doi. org/10.5380/nep.v2i1.45435

Sampaio, F. S. (2015). O terceiro banheiro: fuga da "pedagogia do insulto" e/ou reforço da heteronormatividade. Periódicus, 3(1), 131-151. Disponível em https://periodicos.ufba.br/index.php/ revistaperiodicus/article/view/14259/9861

Santos, A. P. M. T. dos. (2017). Tranças, turbantes e empoderamento de mulheres negras: artefatos de moda como tecnologias de gênero e raça no evento Afro Chic (Dissertação de Mestrado). Universidade Tecnológica Federal do Paraná, Curitiba.

Seffner, F. (2013). Sigam-me os bons: apuros e aflições nos enfrentamentos ao regime da heteronormatividade no espaço escolar. Educação e Pesquisa, 39(1), 145-159. http://dx.doi.org/10.1590/ S1517-97022013000100010

Simões, J. A.; França, I., \& Macedo, M. (2010). Jeitos de corpo: cor/raça, gênero, sexualidade e sociabilidade juvenil no centro de São Paulo. Cadernos Pagu, 35, 37-78. http://dx.doi.org/10.1590/ S0104-83332010000200003

Vergueiro, V. (2015). Por inflexões decoloniais de corpos e identidades de gênero inconformes: uma análise autoetnográfica da cisgeneridade como normatividade (Dissertação de Mestrado). Instituto de Humanidades, Artes e Ciências Professor Milton Santos, Universidade Federal da Bahia, Salvador. 


\title{
É INCLUSÃo COM EXCLUSÃO? SOBRE OS ENTRECRUZAMENTOS DE GÊNERO, RAÇA E SEXUALIDADE NO ESPAÇO ESCOLAR
}

Resumo: Este trabalho busca apresentar as potencialidades, limites e contradições envolvidas na construção de uma instituição escolar inclusiva em termos de gênero e sexualidade na cidade de Maceió-AL. Este artigo deriva de uma pesquisa etnográfica sobre os processos de inclusão e exclusão no espaço escolar, a partir dos entrecruzamentos dos marcadores sociais de gênero, sexualidade, raça, classe e religião. A instituição que será aqui descrita era denominada "inclusiva" e "diversa" por estudantes lésbicas, gays, travestis e transexuais devido à proposta da direção escolar de combate à homofobia. O investimento da gestão escolar não era na desconstrução dos preconceitos existentes entre estudantes e o corpo docente, mas o silenciamento de tais discursos no espaço público. Apesar de seu caráter contraditório, era inegável que estas/es jovens estavam usufruindo de um espaço escolar mais democrático. $\mathrm{O}$ mesmo não pode ser dito sobre os jovens rapazes negros, vistos sob o signo da "ameaça" por alguns profissionais da instituição e entre as/os estudantes.

Palavras-chave: Gênero; Sexualidade; Racialização; Religião; Escola.

\section{IS IT INCLUSION WITH EXCLUSION? ON THE INTERSECTIONS BETWEEN GEN- DER, RACE, AND SEXUALITY IN THE SCHOOL ENVIRONMENT}

\begin{abstract}
This work seeks to present the potentials, limits, and contradictions involved in the construction of an inclusive school institution in terms of gender and sexuality in Maceió, Brazil. This article derives from ethnographic research on the processes of inclusion and exclusion in the school space, from the intersection of social markers of gender, sexuality, race, class, and religion. The institution that will be described here was called "inclusive" and "diverse" by lesbian, gay, transvestite, and transsexual students due to the school board's proposal to combat homophobia. The investment of the school management was not in deconstructing the prejudices existing between students and teachers, but in silencing such discourses in the public space. Despite their contradictory character, it was undeniable that these young women were enjoying a more democratic school space. The same cannot be said about young black boys, seen under the sign of "threat" by some professionals of the institution and among students.
\end{abstract}

Keywords: Gender; Sexuality; Racialization; Religion; School.

RECEBIDO: $27 / 04 / 2020$

APROVADO: $27 / 02 / 2021$ 